\title{
Arab ESL Secondary School Students' Spelling Errors
}

Bandar Mohammad Saeed Al-Sobhi*, Sabariah Md Rashid, Ain Nadzimah Abdullah, Ramiza Darmi

Faculty of Modern Languages and Communication, Universiti Putra Malaysia, Malaysia

Corresponding author: Bandar Mohammad Saeed Al-Sobhi, E-mail: bandarphd@gmail.com

\section{ARTICLE INFO}

Article history

Received: June 18, 2017

Accepted: July 20, 2017

Published: July 31, 2017

Volume: 5 Issue: 3

Conflicts of interest: None

Funding: None

\begin{abstract}
English spelling has always been described by many language researchers and teachers as a daunting task especially for learners whose first language is not English. Accordingly, Arab ESL learners commit serious errors when they spell out English words. The primary objective of this paper is to determine the types as well as the causes of spelling errors made by Arab ESL secondary school students. In order to collect the data, a fifty-word standardised spelling test was administered to seventy Arab student participants. The students' types of spelling errors were detected, analysed and then categorised according to Cook's (1999) classification of errors namely substitution, omission, insertion and transposition. In total, 2,873 spelling errors of various categories were identified. The study findings revealed that errors of substitution constituted the highest percentage of the students' type of errors. In addition, the study indicated that the main causes of the students' spelling errors were possibly attributed to the anomalous nature of the English spelling system, the Arab students' lack of awareness of English spelling rules as well as L1 interference. Despite being conducted in an ESL context, the study was almost consistent with the findings indicated by other studies which were carried out in many Arabic EFL context. The findings suggest that spelling instruction should be emphasised while teaching English and should also be integrated with the skills and subskills of reading, writing, pronunciation and vocabulary in order to develop the students' spelling accuracy.
\end{abstract}

Key words: Arab Students, English Spelling System, ESL Context, L1 Interference, Spelling Errors, Substitution

\section{INTRODUCTION}

Spelling is a complex written language skill, which requires a learner to possess a number of language abilities, including phonological, morphological, visual memory skills, semantic relationships as well as adequate knowledge of spelling rules (Staden, 2010). As such, learning to spell words correctly is considered an important activity for various reasons. One is that accurate spelling makes a reader understand the written message clearly. Thus, a writer should have good competency in spelling in order to convey his written message without making any distraction. Okyere (1990) emphasised that spelling is an essential skill to master because it allows for the clear expression of thought in any written text. Accordingly, spelling is considered one of the indispensable skills in written communication and a principal component of a total language arts curriculum. Warda (2005) stated that spelling also affected the students' written performance, and students with low spelling confidence and skills are expected to write less and more plainly than confident spellers do.

Despite its importance, English spelling presents a considerable challenge to most Arab learners (Al-Jarf, 2010; Bowen, 2011). The large amount of research conducted on spelling error analysis in the Arab countries revealed that
Arab students commit many grievous spelling errors when they write in English. In this respect, some spelling error studies which were undertaken recently (Albalawi, 2016; Albalawi, 2016; Alhaisoni et al., 2015; Al-Saudi, 2013; Ahmad, 2013; Benyo, 2014; Hameed, 2016; Trimasse, 2016) have demonstrated that English spelling is always regarded as a troublesome and challenging skill to Arab learners of English. One of the likely primary causes of this dilemma is the linguistic differences between English and Arabic writing systems. Compared with English, Arabic writing system is regarded regular, i.e. there is almost a consistency between its sounds and letters. However, the lack of one-to-one correspondence between English phonemes and graphemes makes its writing system irregular. Such irregularity creates difficulty to Arab learners and therefore most of them fail to spell out English words accurately.

Although many studies have been carried out addressing the challenges concerning English spelling in the Arab countries, where English is used as a foreign language and learnt merely as a school subject (Al-Seghayer, 2014; Tamran, 2016), there is a lack of research investigating the spelling ability of Arab secondary school students in an ESL environment where English language is used on a daily basis as a second language. 
With this in mind, the primary goal of the current study is to investigate the students' spelling errors committed by the Arab secondary school students at the Saudi School in Malaysia where English has a strong presence in everyday spoken and written communication, and in which the Arab ESL school students are anticipated to possess a moderately higher level of writing skills especially in spelling than many Arab EFL students living in the Arab countries. Accordingly, this study proposes to accomplish two objectives:

1. to identify the major types of spelling errors made by Arab ESL secondary school students.

2. to explore the main causes underlying the Arab ESL secondary school students' spelling errors.

\section{LITERATURE REVIEW}

Researchers in the field of applied linguistics have exerted considerable efforts to explore effective and practical procedures in order to resolve pedagogical as well as learning difficulties. Accordingly, their scholarly research has led to the emergence of three widely known approaches to learners' performance: Contrastive Analysis (CA), Error Analysis (EA) and Interlanguage (IL).

To begin with, the approach of CA compares and contrasts two linguistic systems, i.e. phonetic, syntactic and so forth to surmount L2 difficulties confronting language learners and teachers. The central premise of CA is that language is a set of habit formation, rather than a rule formation, which can be learnt through imitation, practice and reinforcement (Ellis, 1985; Richards \& Schmidt, 2010). This approach considers the learner's first language as a primary cause of the difficulties which he encounters while learning L2. Thus, errors are expected to occur when a learner negatively transfers some linguistic elements, e.g. sounds or structures from his first language to the target language (Selinker and Gass, 2008). However, empirical research carried out by scholars such as Corder (1981), James (1998), and Al-Jarf (2010) indicated that learners' error cannot be merely resulted from their mother tongue interference. In fact, most of the errors which second language learners made suggest that they were gradually developing an L2 rule system, i.e. L2 learners pass through stages of learning whose errors vary from one developmental stage to another (Dulay et al. 1982). Discontent with the CA approach has changed the scholars' focus to a more justifiable and effective procedure of analysing learners' errors, i.e. Error Analysis.

Corder, the proponent of EA, and his followers view learner's errors as an experimental technique, which indicates how a learner's language evolves (1981). According to Benati and VanPatten (2010), EA is a tool that incorporates a set of procedures for identifying, describing and explaining the errors of second language learners. Compared with CA, the approach of EA enables language researchers understand the nature of the L2 learning process deeper. Researchers such as Keshavarz (2003), Nzama (2010) and Zawahreh (2012) assert that conducting EA studies is considered highly significant because it provides researchers with information about the language learning process and how it develops. It also helps teachers identify the difficulties which the students encounter while learning L2 In addition, EA is helpful in preparing tests, classroom activities and suitable teaching materials as well (Sridhar, 1980).

In language learning, scholars have offered many definitions for errors. For example, Corder (1981) describes an error as a systemic defect caused by a learner's lack of linguistic competence. Along the same line, Ferris (2011:3) defines errors as 'morphological, syntactic, and lexical forms that deviate from rules of the target language, violating the expectations of literate adult native speakers.' Thus, learner's errors result from his lack of language knowledge and awareness rather than performance. In this paper, a spelling error refers to any inaccuracy in English words resulting from the student's lack of knowledge of phonology, morphology, orthography and semantics.

Whilst EA solely focuses on the erroneous forms made by the learner owing to their mother tongue and target language, interlanguage (IL) is described as 'an autonomous linguistic system in its own right that evolved according to innate and probably universal processes' (Han \& Tarone, 2014: 8). The major feature which makes the IL hypothesis essentially distinct from CA and EA is that 'it is wholly descriptive and avoids comparison' (James, 1998: 6). Saville-Troike (2006) states that an interlanguage has four salient characteristics. It is systematic, dynamic, variable and reduced in both form and function.

In regard to learners' spelling errors, previous studies carried out in the Arabic EFL context by (Al-Jarf, 2008; Al-Karaki, 2005; Bahloul, 2007and others) revealed that the spelling errors of Arab EFL learners could result from a number of possible causes. For example, researchers such as Al-Karaki (2005), Al Jayousi (2011) and (Ahmad, 2013) claim that the irregularity of English spelling system could be the primary cause of the EFL Arab learners' spelling errors. Al-Karaki (2005) declares that there are six possible causes of Arab EFL learners' errors, namely, pronunciation (i.e. the non-phonetic nature of English), differences between the sound systems of English and Arabic, overgeneralization, inconsistent nature of English word derivation, incomplete application of English spelling rules, or the lack of knowledge of the exceptions of spelling rules, and performance errors. Al Jayousi (2011) divided the spelling errors of Arab EFL learners into four main categories:

1. Irregularity of English contains errors resulted from lack of connection between sounds and letters such as omitting silent letters in words like knew and light.

2. Mother tongue interference includes errors caused by the linguistic differences between English and Arabic systems such as substituting the sound $/ \mathrm{p} /$ for $/ \mathrm{b} /$, e.g. bark for park or /v/ for /f/ as in fan instead of van.

3. Lack of knowledge of spelling rules and their exceptions which can be found in the incorrect application of some spelling rules such as the plural formation, e.g. (*halfs - *partys) instead of (halves and parties).

4. Performance errors which occur due to tiredness or haste such as writing $(*$ fo rather than $o f)$.

Despite the global status which English language enjoys as a language of communication, science and business 
of today's world, the review of spelling literature revealed that most learners of English throughout the world face considerable difficulties in English spelling especially in EFL context, i.e. the Arabic-speaking countries, where there is a limited exposure to English, and it is merely used a school subject.

Benyo (2014) explored English spelling errors committed by first year students studying at Dongola University to discover the factors behind these problems. In order to collect the data, two spelling tests (pre and post intervention) were administrated to 200 Sudanese EFL students in two different faculties. The pre- intervention test was given to the students during their first semester whereas the post- intervention spelling test was administered after two months of the second semester. The study revealed that students face difficulties with English vowels sounds as well as some English sounds which do not exist in Arabic. The study also indicated that the students' unawareness and overgeneralization of English spelling rules might be another primary cause of their spelling errors.

Likewise, Alhaisoni et al. (2015) scrutinized the English spelling errors of 122 male and female EFL Saudi students studying at Ha'il University whose ages ranged from 18 to 20 years. The students were asked to choose from four suggested topics to write a well-organised and coherent essay. They categorised the learners' spelling errors into: omission, substitution, insertion and transposition. The data revealed that the students committed 1,189 spelling errors, and the errors of omission represented the highest percentage of all $39.6 \%$ (462 errors) followed by substitution errors which made up $34.9 \%$ (429 errors). Most of the errors were attributed to the wrong use of vowels and pronunciation. The researchers declare that the main reasons for the errors are the irregularity of English spelling which is clearly visible in the lack of phoneme-grapheme correspondence, and vice versa as well as the students' mother tongue interference.

Similarly, Albalawi (2016) investigated the common spelling errors committed by 80 Saudi female EFL students studying English language as an essential requirement to begin their academic study in Prince Fahad Bin Sultan University. The data were collected through a writing task as well as an English spelling test. The researcher classified the students' spelling errors into four categories: substitution, omission, insertion, and transposition. The analysis of errors established that errors of omission (59\%) constituted the highest proportion of errors followed by the substitution errors $(28.9 \%)$ whereas transposition error category had the least frequency of errors with a percentage mean of (4.3\%). The students' spelling errors were attributed to a number of causes including the wrong use of English vowels, mispronunciation as well as the irregularity of the orthographic system of English and mother tongue interference.

In another study, Hameed (2016) investigated the spelling errors which Saudi students make in English while writing. The subjects of the study included 26 Saudi EFL university students, and the data were collected via a fifty-word dictation. The analysis of the students' responses showed that there was a concentration of errors around vowel sounds, diphthongs and words containing silent letters. About 93\% of the responses turned out to be incorrect. In addition, learners applied their knowledge of mother tongue (i.e. as being a phonetic-based language) on their English learning experience. As far as spelling error type is concerned, the findings revealed that the students the errors of substitution were the highest followed by omission, transposition and then insertion.

In the same way, Albalawi (2016) carried out a study to examine and categorise the spelling errors of the introductory year students at Tabuk University in Saudi Arabia. The study included 45 EFL Saudi participants. The students' spelling errors were classified into three different categories including omission, substitution and addition errors. The findings showed that spelling errors may be related to the non-phonetic nature of English spelling as well as the differences between the sound systems of English and Arabic languages.

All the aforementioned studies attempted to explore spelling errors committed by Arab students in different Arab countries (e.g. Saudi Arabia and Sudan) where English is considered as a foreign language, i.e. not used in everyday written and spoken interactions. The studies revealed that errors of omission and substitution constitute the highest percentage of Arab students' spelling errors. They also indicated that Arab students had grave difficulty in representing English vowels correctly. This could be due the inconsistency between English phonemes and graphemes as well as the students' mother tongue interference. All the studies cited above are related to the current study in that they attempted to accomplish similar objectives, i.e. to examine Arab EFL spelling errors in their writing. However, this study differs from those mentioned studies; this study is devoted to examining the types and causes of the spelling errors made by the Arab ESL secondary school students in the Saudi School in Kuala Lumpur. Unlike in the EFL context, English is used widely in Malaysia and is considered as an official second language used on a daily basis in communication and business contexts after Bahasa Malaysia, the official language of the country (Thirusanku \& Yunus, 2014).

\section{METHODS}

Since the main objective of the current study was to investigate the types and causes of spelling errors made by Arab ESL secondary school students in the Saudi School in Kuala Lumpur, the four-stage procedure proposed by Corder (1974 as cited in Ellis, 1994: 48) for data collection and analysis was adopted as follows:

1. Collection of a sample of learner language, i.e. the spelling errors made by the participants in this study

2. Identification of learners' errors,

3. Description of learners' errors and

4. Explanation of learners' errors.

\section{Data of the study}

Data of the study comprises spelling errors collected via a 50-word spelling test administered to 70 male students 
attending the Saudi School in Kuala Lumpur. The male students were identified and selected via purposive sampling. All the students are from different Arab (e.g. Saudi Arabia, Syria and Iraq) and non-Arab countries (e.g. Malaysia and Singapore) and their age range from 16 to 18 years old. To control for any variation in the sampling, several selection criteria were considered. Firstly, the students are Arab secondary school students who have studied at the Saudi School in Kuala Lumpur, Malaysia for at least two years. Secondly, the students must have the ability to communicate well in English, and this was gauged by a short speaking test, which showed that the students' speaking ability could enable them to communicate well with others. In this study, female students were not included in the study due to the gender segregation policy implemented in the school. Accordingly, no access was given to female students.

\section{Data Collection and Administration}

In this study, a 50-word standardised spelling test, which was developed by Sacre and Masterson (2000), was administered orally in a sixty-minute session. During the administration of the test, each target word was singly read out by the examiner, followed by a meaningful sentence which has the word in context to avoid confusion in recognising the words among the students. The students were only required to write the fifty targeted words in the blank spelling test answer sheet. Each word was repeated three times to allow the students sufficient time for revising and checking their responses. Once the answer sheets were submitted, the students' results were scored as either correct or incorrect.

Accordingly, the data was followed by identifying the students' spelling errors in the corpus. It is worth mentioning that Corder (1981) made a clear distinction between the two notions: 'errors' and 'mistakes'. He states that 'errors' are failures in competence whereas 'mistakes' are failures in performance. He also adds that 'errors' are important because they reflect underlying knowledge, but 'mistakes' are not as they occur due to the learner's memory lapses and physical states such as tiredness, nervousness and so forth. Thus, 'mistakes' do not exhibit the learner's internal linguistic knowledge.

Another essential difference is that 'errors' are not self-rectifiable, i.e. they cannot be corrected by the learner himself whereas 'mistakes' are self-correctable (James, 1998). During the spelling test of this study, each target word was provided by a meaningful sentence, and was dictated three times. The students were given sufficient time for correction and revision while doing the spelling test. Despite the time allotted for word repetition and self-correction, many students were unable to correct the misspelt words. As a result, the students' incorrect spelling was considered 'errors' not 'mistakes'. In fact, the students' inability to self-rectify their errors also reflects their lack of competence in English.

After collecting and identifying the students' errors found in the corpus, the errors are classified into different categories. In this study, the spelling errors found in the Arab ESL students' spelling tests were detected and categorised according to Cook's classification (1999), which divides the students' errors into four main categories: substitution, omission, insertion and transposition. Subsequently, the possible causes of the errors were explained, which is also one of the objectives of the study.

In EA, explaining the causes of learners' errors is considered an exacting task because errors could be attributed to different internal and external factors (Dulay et al., 1982). Corder (1973) states that L1 negative transfer and learner's false hypothesis are regarded as a clear indication which explains a learner's errors. In relation to this, James (1998) proposed four primary causes of errors:

1. Interlingual errors which refer to those errors resulted from the learner's first language.

2. Intralingual errors which include learner's error that are attributed to the target language, e.g. overgeneralisation and false analogy.

3. Communication strategy-based errors which are resulted from using too many words to describe the target word. This happens when a learner cannot recall a specific word and attempts to explain using his own words.

4. Induced errors which result from classroom situations such as teacher-talk, material-based and exercise-based errors.

\section{Data Analysis}

The students' types of spelling errors were categorised according to Cook's classification of errors, which includes:

1. Substitution, which occurs when the learner replaces the right form with an incorrect one like sboon for spoon,

2. Omission, which is the absence of a letter that must appear in a well-formed utterance as in lit for light,

3. Insertion that takes place when an item is incorrectly inserted as in firist instead of first, and

4. Transposition, which is caused by reversing the order of two or more as in fromation for formation.

As far as the causes of Arab EFL students' spelling errors, the literature reviewed, (Ahmad, 2013; Albalawi, 2016; Alhaisoni et al., 2015; Al-Jabri 2003; Al-Jarf, 2008; Al Jayousi, 2011; Al-Karaki, 2005; Al-Mezeini, 2009; Alzuoud 2013; Bahloul, 2007; Benyo, 2014; Hameed, 2016) indicate that the Arab EFL students' spelling errors could result from the following likely causes:

1. The irregular orthographic system of English, which is clearly apparent in the lack of correspondence between English phonemes and graphemes and vice versa. For example, the phoneme $/ \mathrm{k} /$ can be represented in different graphemes or digraphs such as $<\mathrm{k}>$ kit, $<\mathrm{c}>$ car, $<$ ck $>$ back, $<\mathrm{cc}>$ account, $<\mathrm{ch}>$ school, $<\mathrm{q}>$ quiet and so forth. This category also includes the omission of silent letters as in know, night, writing and so on.

2. The lack of awareness of spelling rules which could be attributed the students' limited knowledge of English inflectional morphology such as the inflectional suffixes -s, -ed and -ing, e.g. as in worries, stopped and planning.

3. The first language negative transfer, which occurs as a result of linguistic interference between L1 and L2. For example, Arab EFL learners are expected to incorrectly spell out the words (vast - push) as (fast - bush). This substitution happens due to the fact that the phonemes $/ \mathrm{v} /$ and $/ \mathrm{p} /$ do not almost exist in Arabic. 


\section{RESULTS AND DISCUSSION}

The results of the study are discussed as per objective of the study stated earlier.

\section{The Arab ESL Students' Types of Spelling Errors}

The students' spelling errors were identified, computed and categorised into four major types: substitution, omission, insertion and transposition as shown in Figure 1 below.

Based on the total number of the different types of spelling errors, the overall frequency of the students' spelling errors was 2,873. Among all the errors identified, the substitution category was the most frequent, with a percentage of $43.2 \%$ followed by the errors of omission, which made up $39.8 \%$. This confirms the findings of some studies (Al-Jabri 2003, Al-Mezeini 2009; Alzuoud, 2013 and Hameed, 2016), which indicated that most Arab learners of English commit spelling error due to substituting or omitting a linguistic element, i.e. a letter or sound. However, the categories of insertion and transposition constituted the least common errors found in the corpus, with percentages of $10.5 \%$ and $6.2 \%$ consecutively.

The analysis of the type of spelling errors enabled the researcher to identify three top five misspelt words in each type. It is worth noting that many misspelt words identified in the corpus have multi-category errors, i.e. one word containing two or three types of spelling errors. For example, the word environment was incorrectly written as *inviroment, whereby the grapheme $<\mathrm{e}>$ was wrongly substituted by $<\mathrm{i}>$ and also the letter $<\mathrm{n}>$ was omitted. Accordingly, this word was included in the two categories, substitution and omission as shown in Table 1 below.

Table 1 illustrates the three top misspelt words according to their types. As far as substitution is concerned, the words circumference, entertained and environment were classified as the most frequent misspelt words. It seems that most substitution errors were vowel-based. This could be attributed to the students' wrong pronunciation of English vowel sounds. Consequently, the students were not able to spell out the words correctly. This can obviously be noticed in the misspelt word *sircomfrans, in which the graphemes $<_{\mathrm{u}}-\mathrm{c}>$ were incorrectly replaced by $<_{\mathrm{O}}-\mathrm{s}>$. Similarly, the grapheme $<\mathrm{e}>$ was wrongly substituted by $<\mathrm{i}>$ in $*$ intertaind and $*$ inviroment.

In the category of omission, the words environment, halves and stopped constituted the students' most incorrect words because the silent graphemes $<$ n, $1>$ in these words were left out. Accordingly, the students incorrectly wrote *inviroment, and *haves. In fact, the phenomenon of silent letters which is considered common in English spelling does not almost exist in Arabic. In this case, it is expected that Arab learners of English omit silent letters while writing as the letters are not pronounced. The word stopped was also misspelt as *stoped due to the double consonants, which are represented in two consecutive letters but pronounced as one sound such as apple, call, dress and so forth. Unlike English, Arabic has a phonetic-based spelling system in which words are written as they are pronounced. Thus, an Arab learner

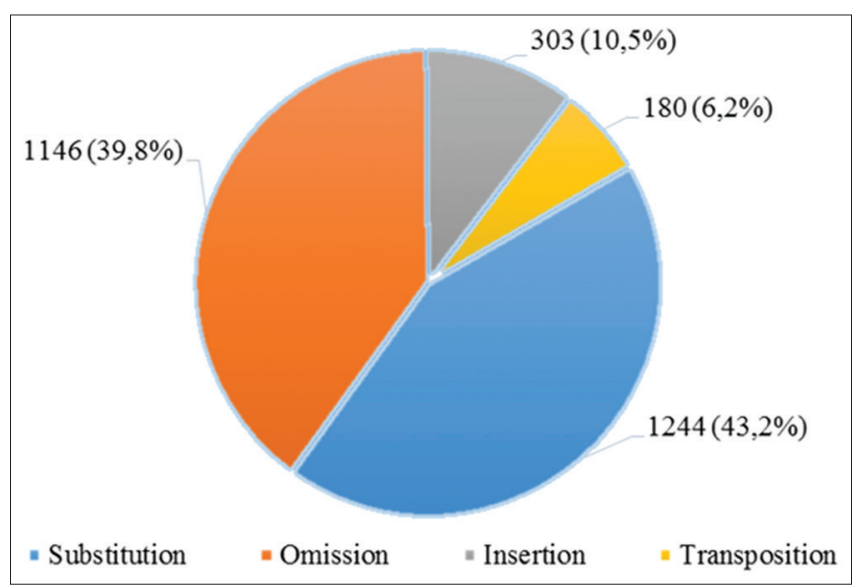

Figure 1. Number of types of spelling errors

Table 1. The three top misspelt words based on type

\begin{tabular}{lll}
\hline Error type & Target words & Misspelt words \\
\hline Substitution & Circumference & Sircomfrans \\
& Entertained & Intertaind \\
& Environment & Inviroment \\
Omission & Environment & Inviroment \\
& Halves & Haves \\
& Stopped & Stoped \\
Insertion & Altogether & Alltogether \\
& Misused & Missused \\
& Misunderstanding & Missunderstanding \\
Transposition & Quietly & Queitly \\
& Treasure & Traeuser \\
& Adventure & Advenuter \\
\hline
\end{tabular}

may misrepresent words containing double consonants and write, e.g. *aple, *cal, and *dres instead of apple, call and dress. These two phenomena, i.e. silent letters and double consonants, are considered perplexing as it increases the possibility of committing spelling errors. In their studies, (Albalawi, 2016; Albalawi, 2016; Alhaisoni et al., 2015) revealed that the highest percentage of the Arab EFL students' spelling errors concentrated on the omission category. This could be attributed to the students' mispronunciation of English words as well as the inconsistent nature of English spelling in which there is no one-to-one correspondence between its graphemes and phonemes. Consequently, Arab students tended to omit silent letters and misrepresent double consonants. The results in this study are consistent with the above reviewed studies, which identified similar types of spelling errors in their writing.

In respect to insertion, the words altogether, misused and misunderstanding were wrongly written as *alltogether, *missused and *missunderstanding. Although the target words were provided with examples when taking the dictation in order to avoid confusion, it seems that such errors could be due to the confusing homophonous words which the students are normally familiar with, i.e. all and miss. Consequently, the students falsely spell the word altogeth$e r$ as all together by inserting the grapheme $<\mathrm{l}>$. Likewise, they incorrectly added the grapheme $<$ s $>$ to the derivational 
prefix mis-. Researchers such as (Al-Jabri, 2003, Al Jayousi, 2011 and many others) claim that English homophones pose a challenge for EFL students. Accordingly, teachers should provide students with a meaningful context to help them spell out the target words easily.

The errors of transposition made up the least errors identified in the study. Such errors resulted from misplacing letters as in *queitly, *traeuser and *advenuter rather than quietly, treasure and adventure. This could be attributed to the lack of correspondence between sounds and letters in English, i.e. one phoneme can have different representations, which appears to be confusing to the Arab students' whose first language is highly phonetic. In this regard, the errors could have resulted as reversing the order of vowel letters when spelling the words.

\section{The Likely Causes of the Arab ESL Students' Spelling Errors}

In light of the literature reviewed, (Ahmad, 2013; Albalawi, 2016; Albalawi, 2016; Alhaisoni et al., 2015; Al-Jarf, 2008; Al Jayousi, 2011; Al-Karaki, 2005; Alzuoud, 2013; Bahloul, 2007; Benyo, 2014; Hameed, 2016) the identified spelling errors of Arab EFL students could be due to intralingual and interlingual causes. The spelling test analysis revealed that the students in the study made 1,304 spelling errors. These errors were attributed to three inferred possible causes (Figure 2), namely:

1. Anomalous nature of English spelling

2. Students' lack of awareness of spelling rules

3. Students' L1 interference.

\section{The anomalous nature of English spelling}

The data analysed indicated that most of the spelling errors made by the Arab ESL students in the Saudi School in Kuala Lumpur could be a result of the anomalous nature of English spelling, which constituted $(62.2 \%)$ of the students' spelling errors. This includes four sub-causes: (a) the mismatch between English phonemes and graphemes (24.4\%), (b) misleading homophones $(17.5 \%)$, (c) silent letters (14\%) and (d) double consonants $(6.2 \%)$.

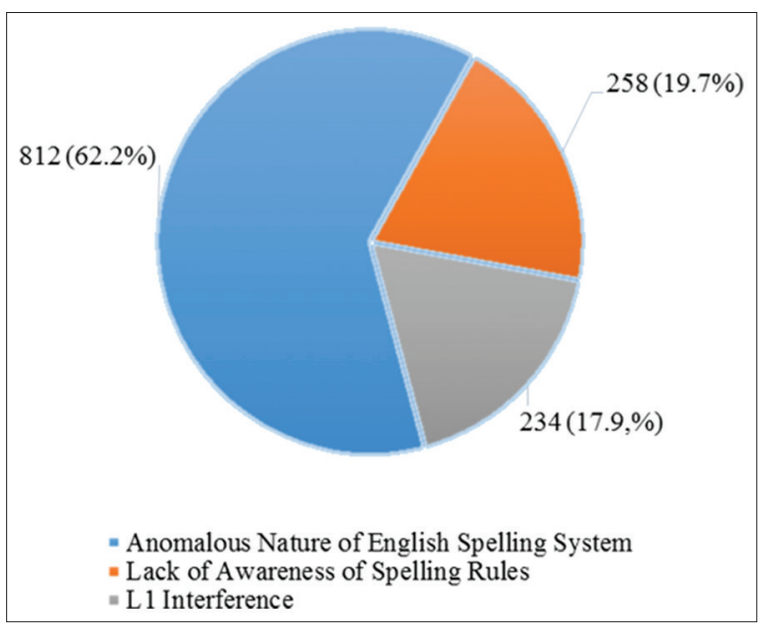

Figure 2. Possible causes of spelling errors
Firstly, the mismatch between phonemes and graphemes makes English spelling unpredictable and illogical. The phoneme /f/, for instance, can have different graphemes $<\mathrm{f}$, ff, ph, ough $>$ as in fat, stuff, phone, and tough consecutively. Second, misleading homophonous linguistic units, i.e. words and syllables having similar sounds but different spellings, are also considered perplexing due to the inconsistency between English sounds and letters. In this study, many students incorrectly wrote miss and full while spelling out *misued and * respectfull. In addition, this mismatch can also be found in words containing silent letters such as night, knew, environment, halves, and writing. Many studies on spelling errors such as (Al Jayousi, 2011; Hameed, 2016) revealed that Arab learners suffer from words with silent letters. This could be attributed to the differences between Arabic and English writing systems. Finally, the least errors in this study were caused by words having double consonants such as glasses, worried and surrounded.

\section{The students' lack of awareness of spelling rules}

Secondly, it was inferred that the Arab ESL students' lack awareness of English spelling rules, especially, the inflectional suffixes -es, -ed, -ing, could have led to their incorrect spelling. Such errors constituted (19.7\%) of the total spelling errors detected in the corpus. Words such as *galssis, *chrchis, *tomatos, *halfs, and *partys were misspelt due to the incorrect insertion of -es inflectional suffix. Likewise, *stoped, *replyed and *worryed were wrongly written, perhaps, due to some students' limited knowledge of the inflectional suffix -ed. Similarly, some students failed to add the inflectional suffix -ing accurately and hence they wrote *planing, *writeng, and *damageing. These results are consistent with (Al Jayousi, 2011; Al-Karaki, 2005) who revealed that the Arab students' inadequate knowledge of spelling rules and morphological changes negatively affects their spelling accuracy. In fact, being aware of the English word structure decreases the possibility of committing spelling errors and makes a proficient speller. This may positively affect the students' writing quality.

\section{The students' 11 interference}

Previous studies carried out on error analysis (Albalawi, 2016; Alhaisoni et al, 2015; Benyo, 2014; Hameed, 2016) revealed that Arab students' L1 interference might be a possible cause of their spelling errors. In this study, L1 interference constituted the least errors identified in the corpus $(17.9 \%)$. It was observed that some students tended to substitute the graphemes $<\mathrm{b}, \mathrm{f}, \mathrm{ch}>$ with $<\mathrm{p}, \mathrm{v}, \mathrm{sh}>$. Thus, it is believed that spelling errors such as *reblied, *resbectful, *adfansher, *discofered, *shair and *shershes seem to be due the incorrect replacement of Arabic phonemes with their English counterparts.

\section{CONCLUSION}

The present study has attempted to identify the major types and causes of spelling errors, which the Arab ESL secondary 
school students made. The study revealed that the linguistic differences between English and Arabic could be one of the primary causes of the students' spelling errors. One of these differences is the representation of vowel sounds in English, which Arab ESL students may not be familiar with due to the different nature of the writing systems in both languages. Moreover, the inconsistency in sounds and spelling could also cause some confusion which leads to spelling errors. Such an inconsistency between phonemes and graphemes may have negatively affected the students' ability to spell out English words correctly. Consequently, the highest percentage of the students' spelling error was concentrated on the substitution category. Differences in the spelling system are not only restricted to vowel sounds, but also include consonants especially those which do not almost exist in Arabic such as $<\mathrm{p}, \mathrm{v}>$ which could be spelt incorrectly due to their mispronunciation as $/ \mathrm{b}, \mathrm{f} /$. In fact, such errors could have also occurred due to the students' L1 interference in which they negatively transfer some similar linguistic elements from their L1 to the target language. The study also revealed that English words containing silent letters and so forth are considered perplexing because they are not pronounced. Therefore, they could be omitted while writing. As such, Arab ESL students are required to give them considerable attention and more practice while learning spelling, and teachers of English should concentrate on such words to minimise the possibility of making such spelling errors. In addition, the study revealed that some Arab ESL students were unaware of the English spelling rule especially the -s, -ed and -ing inflectional endings which constituted the second largest number of the students' spelling errors in this study. Due to the unawareness of spelling rules, some Arab students may incorrectly substitute, insert, omit, or transpose a letter(s) while spelling out English words. Though spelling errors may be regarded as something trivial, for Arab learners, such spelling errors may lead to bigger problems in writing, which thus needs to be given greater attention so as to help learners acquire the basics of writing in English. In this light, it is strongly recommended that that formal spelling instruction should be integrated with reading and writing lessons in the Arab school English curriculum in order to overcome the students' spelling deficiency at the early stage, which in turn, would facilitate the enhancement of both Arab young and adult ESL/EFL learners' writing.

\section{REFERENCES}

Ahmad, M. E. (2013). Errors of English Language Committed by Sudanese Students at Secondary Schools in Khartoum Locality. Postgraduate Diploma in Education. Open University of Sudan.

Albalawi, F. S. (2016). Analytical Study of the Most Common Spelling Errors among Saudi Female Learners of English: Causes and Remedies. Asian Journal of Educational Research, 4(3), 48-62.

Albalawi, M. J. (2016). The Academic Writing Performance and Spelling Errors of English as Foreign Language Students at Tabuk University: A Case of the Introductory
Year Students. Asian Journal of Social Sciences, Arts and Humanities, 4(1).

Alhaisoni, E. Al-Zuoud, M. \& Gaudel, D. (2015). Analysis of Spelling Errors of Saudi Beginner Learners of English Enrolled in an Intensive English Language Program. English Language Teaching, Canadian Center of Science and Education, 8(3).

Al-Jabri, F. M. (2003). Common English Spelling Difficulties of Omani Learners. Oman, Batinah. North Region.

Al-Jarf, R. (2010). Spelling Error Corpora in EFL. Sino-US English Teaching, 7(1), 73.

Al Jayousi, (2011). Spelling Errors of Arab Students: Types, Causes, and Teachers' Responses (master's thesis). American University of Sharjah, the UAE.

Al-Mezeini, H. S. (2009). Does Teaching Spelling Rules Make a Difference? Oman, Batinah North Region.

Al-Saudi, J. (2013). Error Analysis and Spelling Mistakes of EFL Learners at Tafila Technical University: A Case Study. Frontiers of Language and Teaching, 4, 99-107.

Al-Seghayer, K. (2014). The Four Most Common Constraints Affecting English Teaching in Saudi Arabia. International Journal of English Linguistics, 4(5).

Al-Zuoud, K. \& Kabilan, M. (2013). Investigating Jordanian EFL Students' Spelling Errors at Tertiary Level. International Journal of Linguistics, 5(3).

Benyo, A. F. (2014). English Spelling Problems among Students at the University of Dongola, Sudan. International Research Journal. Educational Research, 5(9), 361-367.

Bowen, H. (2011). Spelling it out! Accounting for Spelling Difficulties for Arab Learners of English. Retrieved on $6^{\text {th }}$ May, 2016 from http://marifa.hct.ac.ae.

Cook, V. J. (1999). Teaching spelling. Retrieved March 17, 2015 from www.essex.ac.uk/ vcook.

Corder, S.P. (1973). Introducing Applied Linguistics. Harmondsworth, UK: Penguin Books Ltd.

Corder, S.P. (1981). Error Analysis and Interlanguage. Oxford University Press.

Dulay, H., Burt, M. \& Krashen, S. (1982). Language Two. Oxford University Press.

Ellis, R. (1985). Understanding Second Language Acquisition. Oxford University Press.

Ferris, D. R. (2011). Treatment of Error in Second Language Student Writing. Ann Arbor: The University of Michigan Press.

Hameed, P. F. (2016). A Study of the Spelling Errors committed by Students of English in Saudi Arabia: Exploration and Remedial Measures. Advances in Language and Literacy Studies, 7(1).

Han, Z. \& Tarone, E. (2014). Interlanguage Forty years later. Language Learning and Language Teaching. John Benjamin Publishing Company, Amsterdam.

James, C. (1998). Errors in Language Learning and Use: Exploring Error Analysis. Applied Linguistics and Language Study. Addison Wesley Longman Limited.

Keshavarz, M. H. (2003). Contrastive Analysis and Error Analysis. Tehran: Rahnama Publications. 
Nzama, M. V. (2010). Error Analysis: A Study of Errors Committed by IsiZulu Speaking Learners of English in Selected Schools (Master's thesis), University of Zululand, South Africa.

Okyere, B. A. (1990) Effects of Self-Correction on the Acquisition, Maintenance and Generalization of the Written Spelling of Elementary School Children (Unpublished $\mathrm{PhD}$ Thesis), Ohio State University.

Richards, J. C. \& Schmidt, R. (2010). Longman Dictionary of Language Teaching \&Applied Linguistics ( $4^{\text {th }}$ Ed). Pearson Education Limited.

Sacre, L. and Masterson, J. (2000). Single Word Spelling Test (SWST). Nelson Publishing Company. London.

Selinker, L. \& Gass, S. (2008). Second language acquisition: An introductory course. Mahwah, NJ: Erlbaum.

Sridhar, S. (1980). Contrastive Analysis, Error Analysis and Interlanguage: Three Phases of one Goal. In Croft, K. (ed.). Readings on English as a second Language (pp.91119). Cambridge. Massachusetts: Winthrop publisher.

Staden, A. V. (2010). Improving the Spelling Ability of Grade 3 Learners through Visual Imaging Teaching Strategies. A Journal for Language Learning, Per linguam, 26(1), 13-28.
Tamran, R. (2016). Teaching English as a Second Language in Saudi Arabia. (Unpublished project paper) Effat University, Jeddah.

Thirusanku, J. \& Yunus, M. M. (2014). Status of English in Malaysia. Asian Social Science, 10(14).

Trimasse, N. (2106). Investigating Spelling Errors of Moroccan EFL University Students. Higher Education of Social Science, 10(6), 1-8.

VanPatten, B. \& Benati, A. G. (2010). Key Terms in Second Language Acquisition. London: Continuum International Publishing Group.

Warda, R. (2005) Research based Tutoring of English Spelling. Retrieved on $7^{\text {th }}$ May 2016 from http://files.eric. ed.gov/fulltext/ED492137.pdf.

Younes, Z. \& Albalawi, F. (2015). Exploring the Most Common Types of Writing Problems among English Language and Translation Major Sophomore Female Students at Tabuk University. Asian Journal of Basic and Applied Sciences, 3(2).

Zawahreh, F. A. S. (2012). Applied Error Analysis of Written Production of English Essays of Tenth Grade Students in Ajloun Schools, Jordan. International Journal of Learning and Development. 